\begin{tabular}{|c|l|}
\hline Title & $\begin{array}{l}\text { Reaction dynamics following electron capture of chlorofluorocarbon adsorbed on water cluster : a direct density } \\
\text { functional theory molecular dynamics study }\end{array}$ \\
\hline Author(s) & Tachikawa, Hiroto; A be, Shigeaki \\
\hline Citation & $\begin{array}{l}\text { The Journal of Chemical Physics, 126(19), 194310 } \\
\text { https://doi.org/10.1063/2735320 }\end{array}$ \\
\hline Issue Date & 2007-05-21 \\
\hline Doc URL & http://hdl.handle.net/2115/26417 \\
\hline Rights & Copyright $\odot 2007$ A merican Institute of Physics \\
\hline Type & article \\
\hline File Information & JCP126-19.pdf \\
\hline
\end{tabular}

Instructions for use 


\title{
Reaction dynamics following electron capture of chlorofluorocarbon adsorbed on water cluster: A direct density functional theory molecular dynamics study
}

\author{
Hiroto Tachikawa ${ }^{\text {a) }}$ and Shigeaki Abe \\ Division of Materials Chemistry, Graduate School of Engineering, Hokkaido University, \\ Sapporo 060-8628, Japan
}

(Received 9 March 2007; accepted 4 April 2007; published online 17 May 2007)

\begin{abstract}
The electron capture dynamics of halocarbon and its water complex have been investigated by means of the full dimensional direct density functional theory molecular dynamics method in order to shed light on the mechanism of electron capture of a halocarbon adsorbed on the ice surface. The $\mathrm{CF}_{2} \mathrm{Cl}_{2}$ molecule and a cyclic water trimer $\left(\mathrm{H}_{2} \mathrm{O}\right)_{3}$ were used as halocarbon and water cluster, respectively. The dynamics calculation of $\mathrm{CF}_{2} \mathrm{Cl}_{2}$ showed that both $\mathrm{C}-\mathrm{Cl}$ bonds are largely elongated after the electron capture, while one of the $\mathrm{Cl}$ atoms is dissociated from $\mathrm{CF}_{2} \mathrm{Cl}_{2}^{-}$as a $\mathrm{Cl}^{-}$ ion. Almost all total available energy was transferred into the internal modes of the parent $\mathrm{CF}_{2} \mathrm{Cl}$ radical on the product state, while the relative translational energy of $\mathrm{Cl}^{-}$was significantly low due to the elongation of two $\mathrm{C}-\mathrm{Cl}$ bonds. In the case of a halocarbon-water cluster system, the geometry optimization of neutral complex $\mathrm{CF}_{2} \mathrm{Cl}_{2}\left(\mathrm{H}_{2} \mathrm{O}\right)_{3}$ showed that one of the $\mathrm{Cl}$ atoms interacts with $n$ orbital of water molecules of trimer and the other $\mathrm{Cl}$ atom existed as a dangling $\mathrm{Cl}$ atom. After the electron capture, only one $\mathrm{C}-\mathrm{Cl}$ bond (dangling $\mathrm{Cl}$ atom) was rapidly elongated, whereas the other $\mathrm{C}-\mathrm{Cl}$ bond is silent during the reaction. The dangling $\mathrm{Cl}$ atom was directly dissociated from $\mathrm{CF}_{2} \mathrm{Cl}_{2}^{-}\left(\mathrm{H}_{2} \mathrm{O}\right)_{3}$ as $\mathrm{Cl}^{-}$. The fast $\mathrm{Cl}^{-}$ion was generated from $\mathrm{CF}_{2} \mathrm{Cl}_{2}^{-}\left(\mathrm{H}_{2} \mathrm{O}\right)_{3}$ on the water cluster. The mechanism of the electron capture of halocarbon on water ice was discussed on the basis of the theoretical results. (C) 2007 American Institute of Physics. [DOI: 10.1063/1.2735320]
\end{abstract}

\section{INTRODUCTION}

The emission of chlorofluorocarbons (CFCs) into the Earth's atmosphere causes ozone depletion via solar photolysis of CFCs. ${ }^{1}$ The halogen atom is efficiently generated by photoirradiation to CFCs. ${ }^{2}$ The reactions in the case of $\mathrm{CF}_{2} \mathrm{Cl}_{2}$ (freon 12) are expressed by

$$
\begin{aligned}
\mathrm{CF}_{2} \mathrm{Cl}_{2}+h \nu \text { (solar light) } & \rightarrow \mathrm{CF}_{2} \mathrm{Cl}+\mathrm{Cl}, \\
& \rightarrow \mathrm{CFCl}_{2}+\mathrm{F}
\end{aligned}
$$

The chlorine and fluorine atoms generated from $\mathrm{CF}_{2} \mathrm{Cl}_{2}$ attack the ozone molecules and results in the ozone depletion. However, this situation is different in the winter polar stratosphere due to the presence of polar stratosphere clouds (PSCs). ${ }^{3}$ PSCs consist of water ice or nitric acid ice particles with a major composition of $\mathrm{H}_{2} \mathrm{O}$ and have several kilometers of thickness at very low temperature. Recently, on the basis of data from satellite, balloon, ground state measurement, and laboratory experiment, $\mathrm{Lu}$ and $\mathrm{Sanche}^{4}$ and $\mathrm{Lu}$ and Madey ${ }^{5}$ proposed a model for ozone depletion caused by cosmic-ray ionization of CFCs on PSCs. ${ }^{4,5}$ From their model, it is suggested that a cosmic-ray causes ionization of water ice in PSCs and an electron is generated. The electron attacks CFCs adsorbed on ice and then a negative halogen ion is formed by dissociative electron attachment to CFCs. For ex-

${ }^{\text {a)} F a x:+81 ~ 11706-7897 . ~ E l e c t r o n i c ~ m a i l: ~ h i r o t o @ e n g . h o k u d a i . a c . j p ~}$ ample, the electron capture reaction of $\mathrm{CF}_{2} \mathrm{Cl}_{2}$ is expressed by

$$
\mathrm{CF}_{2} \mathrm{Cl}_{2}+e^{-} \rightarrow\left[\mathrm{CF}_{2} \mathrm{Cl}_{2}\right]^{-} \rightarrow \mathrm{CF}_{2} \mathrm{Cl}+\mathrm{Cl}^{-}
$$

It is known that the cross section of dissociative electron attachment to CFCs at electron energy near $0 \mathrm{eV}$ [reaction (2) in gas phase] is three to four orders of magnitude higher than the corresponding photodissociation cross sections [reactions (1a) and (1b)]. Therefore, it is considered that reaction (2) on ice is dominant in PSCs. The similar conclusion has been obtained by Perry et al. using a combination of reflection absorption infrared spectroscopy, $\mathrm{x}$-ray photoelectron spectroscopy, and temperature programmed desorption. ${ }^{7,8}$ During x-ray irradiation, the dominance of $\mathrm{Cl}^{-}$ anions was formed by the reaction with low-energy secondary electrons. They concluded that that $\mathrm{C}-\mathrm{Cl}$ bond cleavage of $\mathrm{CF}_{2} \mathrm{Cl}_{2}$ via dissociative electron attachment [reaction (2)] is the dominant initial process.

Reactions of molecules adsorbed on water ice have attracted much attention because of their relevance in atmospheric processes. ${ }^{9,10}$ Ice mediates chemical- and radiationinduced processes in interstellar, cometary, and planetary conditions. ${ }^{11}$ Hence, interactions of the molecules with the ice surface have been investigated using thermal desorption spectroscopy, infrared absorption spectroscopy, and x-ray photoelectron spectroscopy ${ }^{12,13}$ for chlorodifluoromethane, trichlorofluoromethane, ammonia, and ozone.

Theoretical calculations were carried out to study the interactions of small nonpolar molecules, ${ }^{14}$ acetone and 
TABLE I. Optimized geometrical parameters of $\mathrm{CF}_{2} \mathrm{Cl}_{2}$ and $\mathrm{CF}_{2} \mathrm{Cl}_{-}-\mathrm{Cl}^{-}$. Bond lengths and angles are in $\AA$ and in degrees, respectively.

\begin{tabular}{clcccccc}
\hline \hline \multicolumn{1}{c}{ Method } & $R_{1}$ & $R_{2}$ & $R_{3}$ & $\theta$ & $\phi_{1}$ & $\phi_{2}$ \\
\hline \multirow{2}{*}{$\mathrm{CF}_{2} \mathrm{Cl}_{2}$} & B3LYP/6-311++G $(d, p)$ & 1.7794 & 1.3377 & & 112.1 & 107.8 & 109.8 \\
& MP2/6-311++G $(d, p)$ & 1.7539 & 1.3373 & & 112.3 & 107.4 & 109.2 \\
& MP4SDQ/6-311++G(d,p) & 1.4587 & 1.3360 & & 112.4 & 107.4 & 109.2 \\
& QCISD/6-311++G $(d, p)$ & 1.7586 & 1.3356 & & 112.4 & 107.4 & 109.2 \\
& & & & & & & \\
$\mathrm{CF}_{2} \mathrm{Cl}-\mathrm{Cl}^{-}$ & $\mathrm{B} 3 \mathrm{LYP} / 6-311++\mathrm{G}(d, p)$ & 2.5089 & 1.9063 & 1.3470 & 127.7 & 106.2 & 106.4 \\
& $\mathrm{MP} 2 / 6-311++\mathrm{G}(d, p)$ & 2.4560 & 1.8143 & 1.3476 & 123.7 & 106.5 & 107.9 \\
& MP4SDQ/6-311++G(d,p) & 2.5612 & 1.8662 & 1.3483 & 122.9 & 103.3 & 109.5 \\
& $\mathrm{QCISD} / 6-311++\mathrm{G}(d, p)$ & 2.5531 & 1.7997 & 1.3427 & 121.9 & 106.9 & 108.7 \\
\hline \hline
\end{tabular}

methanol, ${ }^{15}$ hydrogen chloride, and hydrogen fluoride ${ }^{16}$ with ice surfaces. Although many investigations for the molecules on ice have been carried out by several groups, the works for the electron capture dynamics are limited. ${ }^{17-19}$ In particular, there is no theoretical work for the electron capture dynamics of halocarbon on ice.

In the present study, the electron capture dynamics of $\mathrm{CF}_{2} \mathrm{Cl}_{2}$, reaction (2), has been investigated by means of the direct density functional theory (DFT) molecular dynamics (MD) method to elucidate the mechanism of the electron capture processes of $\mathrm{CF}_{2} \mathrm{Cl}_{2}$. In addition, the effects of water cluster on the reaction dynamics of $\mathrm{CF}_{2} \mathrm{Cl}_{2}$ are also investigated. A cyclic water trimer $\left(\mathrm{H}_{2} \mathrm{O}\right)_{3}$ is examined as the water cluster. The reaction is expressed by

$$
\begin{aligned}
\mathrm{CF}_{2} \mathrm{Cl}_{2}\left(\mathrm{H}_{2} \mathrm{O}\right)_{3}+e^{-} & \rightarrow\left[\mathrm{CF}_{2} \mathrm{Cl}_{2}\left(\mathrm{H}_{2} \mathrm{O}\right)_{3}\right]^{-} \\
& \rightarrow \mathrm{CF}_{2} \mathrm{Cl}\left(\mathrm{H}_{2} \mathrm{O}\right)_{3}+\mathrm{Cl}^{-} .
\end{aligned}
$$

In particular, we focus our attention mainly on comparison with the mechanisms of the electron capture dynamics of $\mathrm{CF}_{2} \mathrm{Cl}_{2}$ in gas phase and on water cluster.

In a previous paper, we investigated the ionization and electron capture processes of $\mathrm{CCl}_{4}$ molecule using direct ab initio MD method. ${ }^{20}$ The mechanism and time scale of the reaction were determined, although the calculations were carried out at the Hartree-Fock (HF) level with a small basis set $\left(\mathrm{HF} / 3-21 \mathrm{G}^{*}\right.$ level). In the present work, we extended the technique to the electron capture process of $\mathrm{CF}_{2} \mathrm{Cl}_{2}$ on the water cluster which plays an important role in PSCs. Also, the B3LYP/6-311++G $(d, p)$ level is used in the direct DFT-MD calculation, which gives a reasonable energetics of the present reaction system.

\section{COMPUTATIONAL METHODS}

Direct DFT-MD calculation was carried out at the B3LYP/6-311++G $(d, p)$ level of theory throughout. The neutral state of $\mathrm{CF}_{2} \mathrm{Cl}_{2}$ was fully optimized by the energy gradient method. Next, several geometries were randomly generated around the equilibrium point of $\mathrm{CF}_{2} \mathrm{Cl}_{2}$, and then the trajectories for anionic system were run from these generated points on the assumption of vertical electron attachment. The electronic state of the system was monitored during the simulation. We confirmed carefully that the electronic state is kept during the reaction. The similar calculation was carried out for $\mathrm{CF}_{2} \mathrm{Cl}_{2}$ water cluster system $\mathrm{CF}_{2} \mathrm{Cl}_{2}-\left(\mathrm{H}_{2} \mathrm{O}\right)_{3}$ to elucidate the effect of adsorption on the water cluster. We chose a cyclic water trimer as a model of water cluster.

The velocities of atoms at the starting point were assumed to be zero (i.e., momentum vector of each atom is zero). The equations of motion for $n$ atoms in a molecule are given by

$$
\begin{aligned}
& \frac{d Q_{i}}{d t}=\frac{\partial H}{\partial P_{j}}, \\
& \frac{\partial P_{j}}{\partial t}=-\frac{\partial H}{\partial Q_{j}}=-\frac{\partial U}{\partial Q_{j}},
\end{aligned}
$$

where $j=1-3 N, H$ is the classical Hamiltonian, $Q_{j}$ is the Cartesian coordinate of the $j$ th mode, and $P_{j}$ is conjugated momentum. These equations were numerically solved by the Runge-Kutta method. No symmetry restriction was applied to the calculation of the energy gradients. The time step size was chosen as $0.10 \mathrm{fs}$, and a total of 10000 or 20000 steps were calculated for each dynamics calculation. The drift of the total energy is confirmed to be less than $10^{-3} \%$ throughout at all steps in the trajectory. The momentum of the center of mass and the angular momentum were assumed to zero. More details of the direct MD calculations are described elsewhere. $^{21,22}$

Static $a b$ initio and DFT calculations were carried out using GAUSSIAN03. ${ }^{23}$ To confirm the stability of the molecules at all stationary points, harmonic vibrational frequencies were calculated at the B3LYP/6-311++ $\mathrm{G}(d, p)$ level of theory. All vibrational frequencies obtained were positive, indicating that the all stationary points were located at the local minima on the potential energy surface. The relative energies were also calculated at the MP2, MP4SDQ, and QCISD levels of theory.

\section{RESULTS}

\section{A. Structures of $\mathrm{CF}_{2} \mathrm{Cl}_{2}$ and $\mathrm{CF}_{2} \mathrm{Cl}_{2}$ anion}

First, the structures of neutral $\mathrm{CF}_{2} \mathrm{Cl}_{2}$ is optimized at the $\mathrm{B} 3 \mathrm{LYP} / 6-311++\mathrm{G}(d, p)$ level of theory. The optimized parameters are given in Table $\mathrm{I}$. The $\mathrm{C}-\mathrm{Cl}$ and $\mathrm{C}-\mathrm{F}$ bond lengths $\left(R_{1}\right.$ and $\left.R_{2}\right)$ and angles $\left(\theta, \phi_{1}\right.$, and $\left.\phi_{2}\right)$ are calculated to be $R_{1}=1.779 \AA, R_{3}=1.338 \AA, \theta=112.1^{\circ}, \phi_{1}=107.8^{\circ}$ and $\phi_{2}=109.2^{\circ}$, respectively, where the angles, $\theta, \phi_{1}$, and $\phi_{2}$, are $<\mathrm{Cl}-\mathrm{C}-\mathrm{Cl}^{\prime},<\mathrm{F}-\mathrm{C}-\mathrm{F}^{\prime}$, and $<\mathrm{Cl}-\mathrm{C}-\mathrm{F}$, respectively. The optimized structure of $\mathrm{CF}_{2} \mathrm{Cl}_{2}$ is illustrated in Fig. 1(a). The 

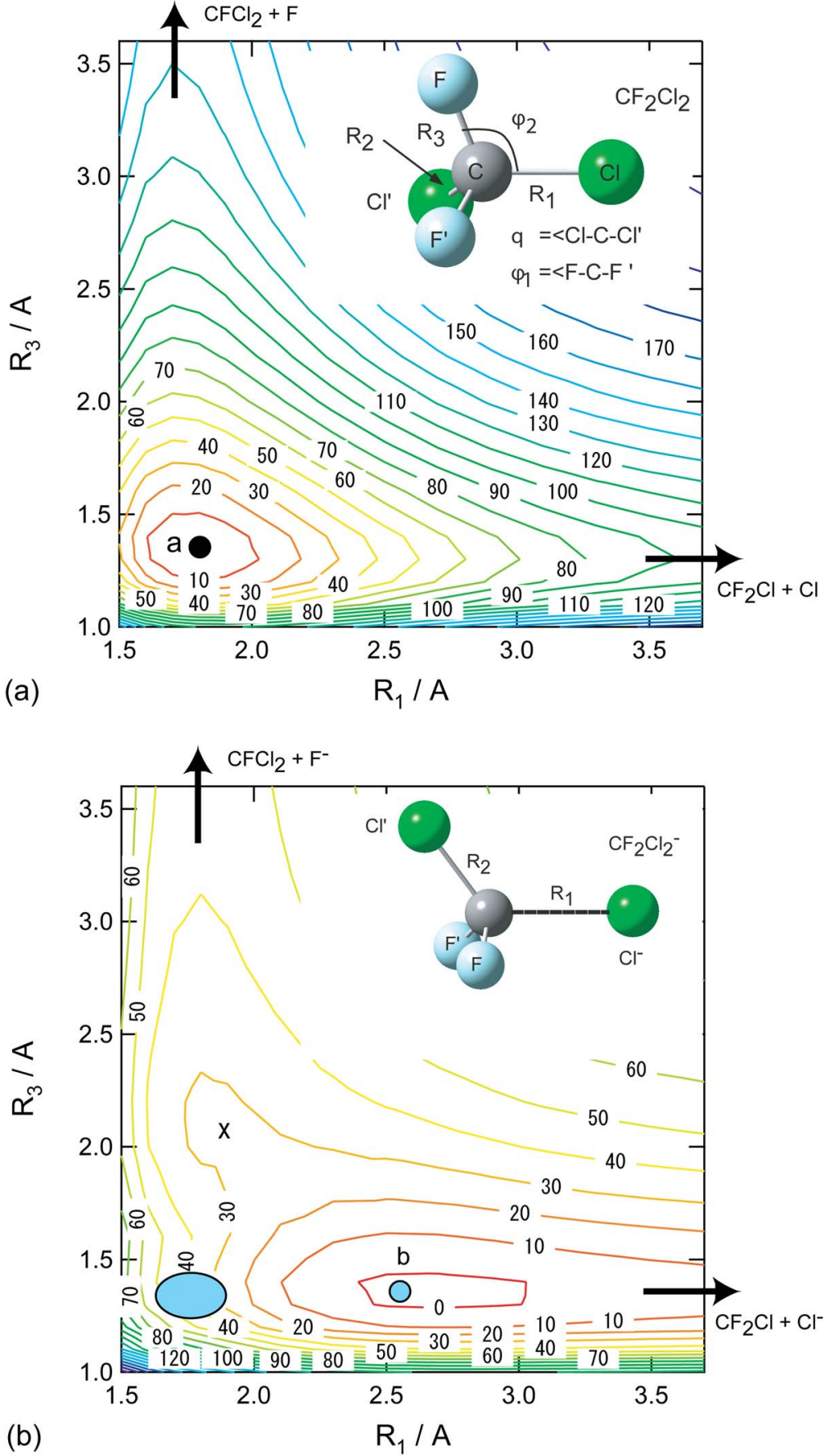

FIG. 1. Potential energy surfaces for the halogen dissociation reactions of (A) $\mathrm{CF}_{2} \mathrm{Cl}_{2}$ and $(\mathrm{B}) \mathrm{CF}_{2} \mathrm{Cl}_{2}^{-}$anion calculated at the B3LYP/6-311++ $\mathrm{G}(d, p)$ level. Contours are plotted by each $10 \mathrm{kcal} / \mathrm{mol}$ interval. The optimized structures of neutral $\mathrm{CF}_{2} \mathrm{Cl}_{2}$ and anion $\mathrm{CF}_{2} \mathrm{Cl}_{2}^{-}$ are illustrated in insert figures. Notations $a$ and $b$ mean the optimized points for neutral and anion states, respectively. contour plot of the potential energy surface for the neutral $\mathrm{CF}_{2} \mathrm{Cl}_{2}$ molecule is illustrated as functions of $R_{1}=r(\mathrm{C}-\mathrm{Cl})$ and $R_{3}=r(\mathrm{C}-\mathrm{F})$ in Fig. 1. The other geometrical parameters are fixed to those of the optimized structure of the neutral $\mathrm{CF}_{2} \mathrm{Cl}_{2}$ molecule. For the neutral state, only one energy minimum corresponding to the equilibrium point of neutral $\mathrm{CF}_{2} \mathrm{Cl}_{2}$ is obtained at $R_{1}=1.779$ and $R_{3}=1.338 \AA$ (denoted by a in Fig. 1). The curvature for the $\mathrm{C}-\mathrm{F}$ direction is more tight than that for the $\mathrm{C}-\mathrm{Cl}$ direction because the $\mathrm{C}-\mathrm{F}$ stretching mode is larger than that of the $\mathrm{C}-\mathrm{Cl}$ stretching mode $\nu(\mathrm{C}-\mathrm{F})=1131 \mathrm{~cm}^{-1} \quad$ (asymmetric $\mathrm{C}-\mathrm{F}$ stretching mode) and $\nu(\mathrm{C}-\mathrm{Cl})=875 \mathrm{~cm}^{-1}$ (asymmetric $\mathrm{C}-\mathrm{Cl}$ stretching mode). From these results, it is found that two dissociation channels would be competitive in the thermal decomposition of $\mathrm{CF}_{2} \mathrm{Cl}_{2}$, namely, $\mathrm{Cl}$ and $\mathrm{F}$ atoms can dissociate from $\mathrm{CF}_{2} \mathrm{Cl}_{2}$, although the dissociation needs large energies. The dissociation energies for the $\mathrm{Cl}$ and $\mathrm{F}$ atoms are calculated to be 73.3 and $108.6 \mathrm{kcal} / \mathrm{mol}$, respectively. The energetics shows that the former channel is energetically more favored than the latter in the thermal decomposition at the neutral state.

The structures of $\mathrm{CF}_{2} \mathrm{Cl}_{2}^{-}$anion are illustrated in Fig. 1 and optimized parameters are given in Table $\mathrm{I}$. The $\mathrm{C}-\mathrm{Cl}$ and C-F bond lengths of $\mathrm{CF}_{2} \mathrm{Cl}_{2}^{-}$are calculated to be $R_{1}$ $=2.510 \AA, R_{2}=1.906 \AA$, and $R_{3}=1.347 \AA$, indicating that one of the $\mathrm{C}-\mathrm{Cl}$ bonds of the $\mathrm{CF}_{2} \mathrm{Cl}_{2}^{-}$anion is largely elongated by accepting an excess electron. In the $\mathrm{CF}_{2} \mathrm{Cl}_{2}^{-}$anion, the negative charge is fully localized on the elongated $\mathrm{Cl}^{-}$ 

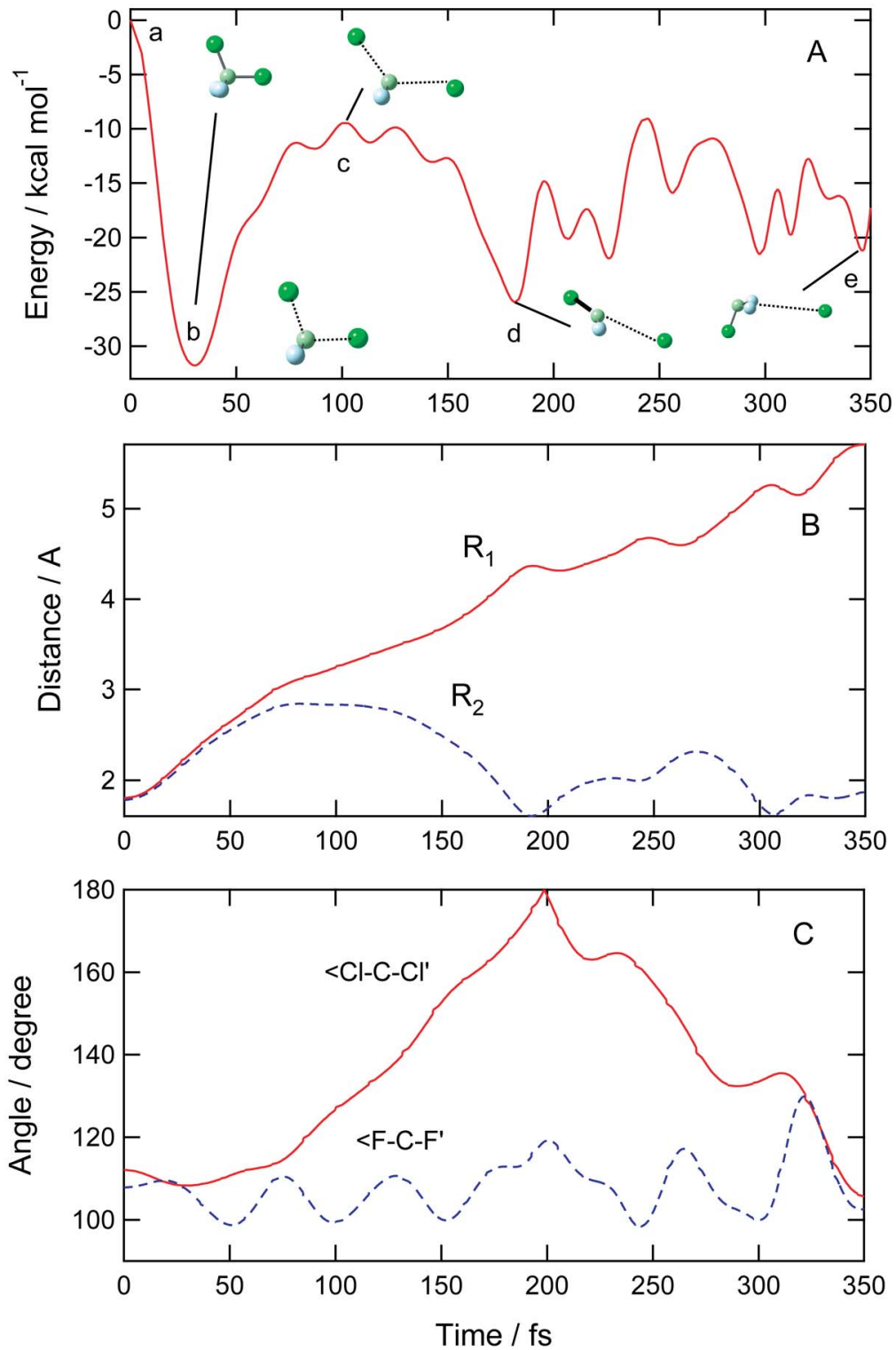

FIG. 2. (Color online) Time propagations of the potential energy (A), distances $\left(R_{1}\right.$ and $\left.R_{2}\right)(\mathrm{B})$, and angles $\left(<\mathrm{Cl}-\mathrm{C}-\mathrm{Cl}^{\prime}\right.$ and $\left.<\mathrm{F}-\mathrm{C}-\mathrm{F}^{\prime}\right)$ for the electron capture reaction of $\mathrm{CF}_{2} \mathrm{Cl}_{2}$. No symmetry restriction was applied in the calculation. The direct DFT-MD calculation was carried out at the B3LYP/6-311++ $\mathrm{G}(d, p)$ level.

ion, while the structure of the $\mathrm{CF}_{2} \mathrm{Cl}$ moiety of $\mathrm{CF}_{2} \mathrm{Cl}_{2}^{-}$is closed to free $\mathrm{CF}_{2} \mathrm{Cl}$ radical. The spin density is mainly localized on the carbon atom of $\mathrm{CF}_{2} \mathrm{Cl}$. From these results, it is found that the $\mathrm{CF}_{2} \mathrm{Cl}_{2}^{-}$anion is composed of a contact radical-ion complex expressed by $\mathrm{CF}_{2} \mathrm{Cl}-\mathrm{Cl}^{-}$. It is considered that a complex expressed by $\mathrm{CFCl}_{2}-\mathrm{F}^{-}$, which has an elongated $\mathrm{C}-\mathrm{F}$ bond, may be possible in the case of $\mathrm{CF}_{2} \mathrm{Cl}_{2}^{-}$. We examined several initial structures to obtain the $\mathrm{CF}_{2} \mathrm{Cl}-\mathrm{F}^{-}$complex in the geometry optimization. However, all calculations give only the structure of the $\mathrm{CF}_{2} \mathrm{Cl}-\mathrm{Cl}^{-}$ complex.

The contour plot of the potential energy surface for the $\mathrm{CF}_{2} \mathrm{Cl}_{2}^{-}$anion is illustrated as functions of $R_{1}$ and $R_{3}$ in Fig. 1 (lower). The other geometrical parameters are fixed to those of $\mathrm{CF}_{2} \mathrm{Cl}_{2}^{-}$. For the anionic state, one energy minimum corresponding to $\mathrm{CF}_{2} \mathrm{Cl}-\mathrm{Cl}^{-}$complex is obtained at $R_{1}$ $=2.510$ and $R_{3}=1.347 \AA$ (denoted by b). The plateau corresponding to $\mathrm{CFCl}_{2}-\mathrm{F}^{-}$complex is found around $R_{1}=1.80$ and $R_{3}=2.05 \AA$ (denoted by cross $x$ ). However, this point is not bound and the geometry optimization from this point leads spontaneously to the $\mathrm{CF}_{2} \mathrm{Cl}-\mathrm{Cl}^{-}$complex. The FranckCondon region for the electron capture of $\mathrm{CF}_{2} \mathrm{Cl}_{2}$ is schematically illustrated in Fig. 1 as hatched region. As clearly seen in this figure, the FC region is largely far from the energy minimum of the $\mathrm{CF}_{2} \mathrm{Cl}-\mathrm{Cl}^{-}$complex. This result indicates strongly that the large structural deformation of $\mathrm{CF}_{2} \mathrm{Cl}_{2}$ takes place after the electron capture. Also, it is found that the potential energy surface (PES) for the anionic state is very complicated. Therefore, the full dimensional direct DFT-MD is the most effective method to obtain the electron capture dynamics of $\mathrm{CF}_{2} \mathrm{Cl}_{2}$.

The energetics for reaction (2) is briefly summarized here. By the vertical electron capture of $\mathrm{CF}_{2} \mathrm{Cl}_{2}$ (a), the reaction point is changed to the anionic state of $\mathrm{CF}_{2} \mathrm{Cl}_{2}$ expressed by $\left[\mathrm{CF}_{2} \mathrm{Cl}_{2}^{-}\right]_{\mathrm{ver}}$. This point is $40.2 \mathrm{kcal} / \mathrm{mol}$ higher in energy than the $\mathrm{CF}_{2} \mathrm{Cl}-\mathrm{Cl}^{-}$complex (b) at the $\mathrm{B} 3 \mathrm{LYP} / 6-311++\mathrm{G}(d, p)$ level. The complex (b) is $14.2 \mathrm{kcal} / \mathrm{mol}$ lower in energy than that of the dissociation limit $\left(\mathrm{CF}_{2} \mathrm{Cl}+\mathrm{Cl}^{-}\right)$, while the vertical electron affinity and total available energy are 40.2 and $26.0 \mathrm{kcal} / \mathrm{mol}$, 


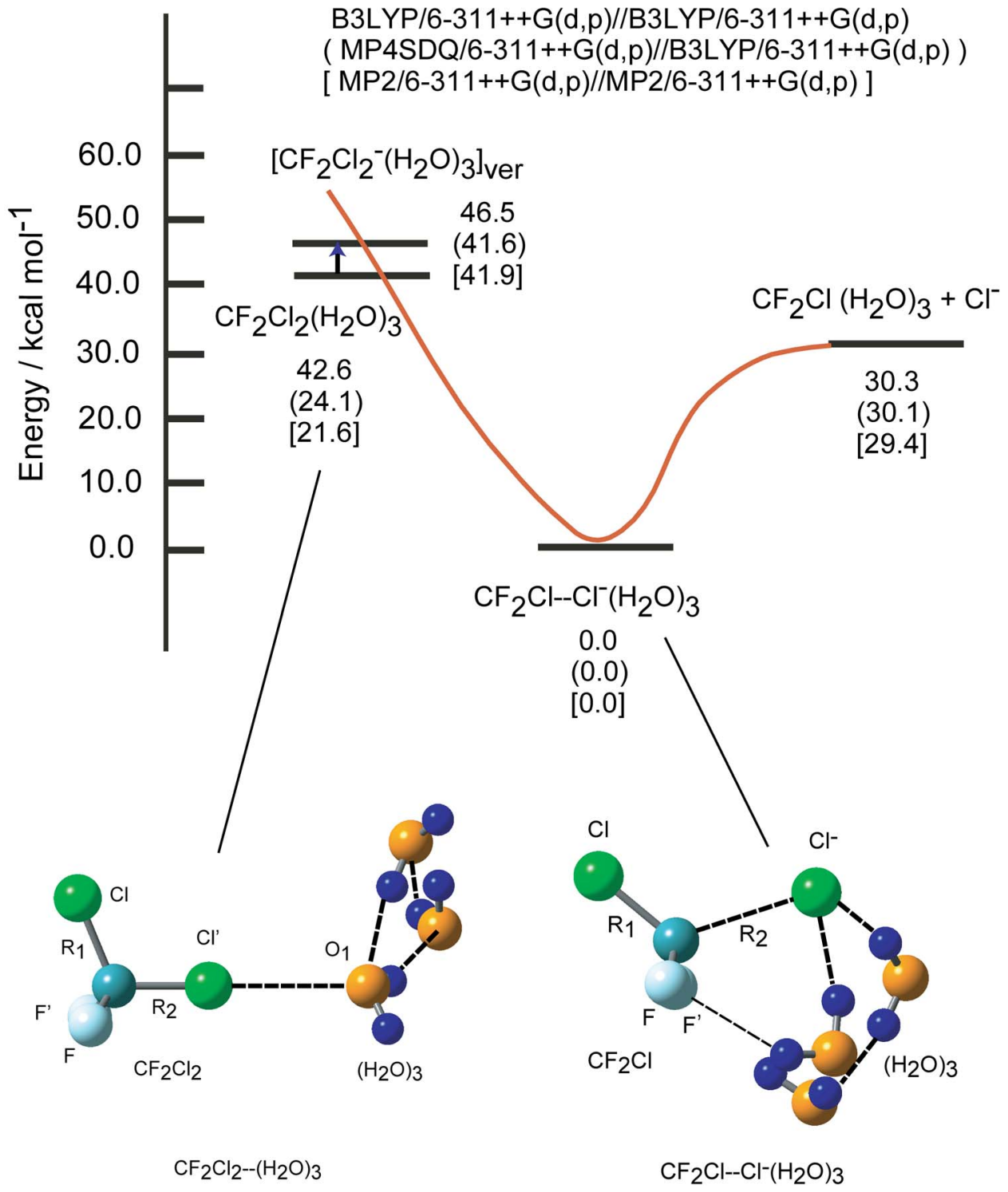

FIG. 3. (Color online) Potential energy diagram for the electron capture process for the $\mathrm{CF}_{3} \mathrm{Cl}_{2}\left(\mathrm{H}_{2} \mathrm{O}\right)_{3}$ system. The optimized structures of neutral and anionic states of $\mathrm{CF}_{3} \mathrm{Cl}_{2}\left(\mathrm{H}_{2} \mathrm{O}\right)_{3}$ are also given. respectively. The MP2/6-311++ $\mathrm{G}(d, p) \| \mathrm{B} 3 \mathrm{LYP} / 6-311+$ $+\mathrm{G}(d, p)$ calculations give the dissociation energy $(9.2 \mathrm{kcal} / \mathrm{mol})$, vertical electron affinity $(36.9 \mathrm{kcal} / \mathrm{mol})$, and total available energy $(27.7 \mathrm{kcal} / \mathrm{mol})$, which are reasonable agreement with those of the B3LYP/6-311+ $+\mathrm{G}(d, p)$ calculations.

\section{B. Electron capture dynamics of $\mathrm{CF}_{2} \mathrm{Cl}_{2}$}

The results of the direct DFT-MD calculation for electron capture of $\mathrm{CF}_{2} \mathrm{Cl}_{2}$ are given in Fig. 2. The $\mathrm{CF}_{2} \mathrm{Cl}_{2}$ molecule has the neutral structure at time zero (point $a$ ), where the $\mathrm{C}-\mathrm{Cl}$ and $\mathrm{C}-\mathrm{F}$ bond lengths are 1.779 and $1.338 \AA$, respectively. After an electron capture, the structure of $\mathrm{CF}_{2} \mathrm{Cl}_{2}^{-}$ is suddenly deformed: Two $\mathrm{C}-\mathrm{Cl}$ bonds are significantly elongated as a function of time. Subsequently, the energy of the system $\mathrm{CF}_{2} \mathrm{Cl}_{2}^{-}$decreases suddenly as time increases, as shown in Fig. 2(a). At time $=30 \mathrm{fs}$ (point $b$ ), the potential energy reaches a minimum point where two $\mathrm{C}-\mathrm{Cl}$ bonds are elongated to be $R_{1}=2.272$ and $R_{2}=2.216 \AA$, respectively, indicating that both bonds are largely elongated after the electron capture. This elongation occurred almost equivalently:
The distances $R_{1}$ and $R_{2}$ are 2.659 and $2.565 \AA$ at 50 fs. After that, one of the $\mathrm{C}-\mathrm{Cl}$ bonds $\left(R_{1}\right)$ is further elongated, but the other one $\left(R_{2}\right)$ is gradually shortened. At point $d$, the distance $\left(R_{2}\right)$ becomes a normal distance $\left(R_{2}=1.802 \AA\right)$, but $R_{1}$ is further elongated. Finally, the trajectory reaches a product region: $\mathrm{CF}_{2} \mathrm{Cl}+\mathrm{Cl}^{-}$(point $e$ ).

The $\mathrm{C}-\mathrm{Cl}$ bond $\left(R_{2}\right)$ reaches $2.835 \AA$ at $100 \mathrm{fs}$, which is $1.056 \AA$ longer than that of the equilibrium distance, so that the $\mathrm{C}-\mathrm{Cl}$ stretching mode of the parent $\mathrm{CF}_{2} \mathrm{Cl}$ radical is vibrationally excited at nacent state. Also, the $\mathrm{F}-\mathrm{C}-\mathrm{F}$ bending mode is excited. The amplitude of the $\mathrm{F}-\mathrm{C}-\mathrm{F}$ bending mode is gradually enhanced around $300 \mathrm{fs}$, indicating that the energy transfer takes place from the $\mathrm{C}-\mathrm{Cl}$ stretching to the $\mathrm{F}-\mathrm{C}-\mathrm{F}$ bending mode. The relative center-of-mass translational energy between $\mathrm{Cl}^{-}$and $\mathrm{CF}_{2} \mathrm{Cl}$ is calculated to be $2.4 \mathrm{kcal} / \mathrm{mol}$ for the sample trajectory, which corresponds to $9.3 \%$ of the total available energy $(26.0 \mathrm{kcal} / \mathrm{mol})$. This indicates that almost all available energy is transferred into the internal energy of the parent $\mathrm{CF}_{2} \mathrm{Cl}$ radical.

Snapshots of $\mathrm{CF}_{2} \mathrm{Cl}_{2}^{-}$after the vertical electron capture of the neutral state are illustrated in Fig. 2 as insert figures. After the electron capture, it is shown that both $\mathrm{C}-\mathrm{Cl}$ bonds 
TABLE II. Optimized geometrical parameters of $\mathrm{CF}_{2} \mathrm{Cl}_{2}\left(\mathrm{H}_{2} \mathrm{O}\right)_{3}$ and $\mathrm{CF}_{2} \mathrm{Cl}-\mathrm{Cl}^{-}\left(\mathrm{H}_{2} \mathrm{O}\right)_{3}$. Bond lengths and angles are in $\AA$ and in degrees, respectively.

\begin{tabular}{ccccccccc}
\hline \hline & Method & $R_{1}$ & $R_{2}$ & $R_{3}$ & $\theta$ & $\phi_{1}$ & $\phi_{2}$ & $r_{1}$ \\
\hline $\mathrm{CF}_{2} \mathrm{Cl}_{2}\left(\mathrm{H}_{2} \mathrm{O}\right)_{3}$ & $\mathrm{~B} 3 \mathrm{LYP} / 6-311 \mathrm{G}(d, p)$ & 1.790 & 1.777 & 1.336 & 112.1 & 107.9 & 108.7 & 2.917 \\
& & 8 & 5 & 2 & & & & 9 \\
& $\mathrm{~B} 3 \mathrm{LYP} / 6-311+\mathrm{G}(d, p)$ & 1.784 & 1.771 & 1.341 & 112.4 & 107.4 & 108.8 & 2.990 \\
& & 7 & 0 & 2 & & & & 8 \\
& $\mathrm{~B} 3 \mathrm{LYP} / 6-311++\mathrm{G}(d, p)$ & 1.785 & 1.770 & 1.341 & 112.3 & 107.4 & 108.8 & 2.985 \\
& & 0 & 9 & 4 & & & & 4 \\
& $\mathrm{MP} 2 / 6-311++\mathrm{G}(d, p)$ & 1.751 & 1.749 & 1.341 & 112.8 & 106.8 & 109.1 & 3.358 \\
& & 4 & 2 & 5 & & & & 6 \\
$\mathrm{CF}_{2} \mathrm{Cl}-\mathrm{Cl}^{-}\left(\mathrm{H}_{2} \mathrm{O}\right)_{3}{ }_{3}$ & $\mathrm{~B} 3 \mathrm{LYP} / 6-311 \mathrm{G}(d, p)$ & 1.822 & 2.670 & 1.350 & 121.5 & 106.9 & 108.6 & 2.204 \\
& & 9 & 5 & 7 & & & & 9 \\
& $\mathrm{~B} 3 \mathrm{LYP} / 6-311+\mathrm{G}(d, p)$ & 1.810 & 2.660 & 1.351 & 121.5 & 106.7 & 109.0 & 2.164 \\
& & 0 & 5 & 8 & & & & 4 \\
& $\mathrm{~B} 3 \mathrm{LYP} / 6-311++\mathrm{G}(d, p)$ & 1.810 & 2.660 & 1.351 & 121.5 & 106.7 & 109.0 & 2.164 \\
& & 1 & 5 & 8 & & & & 4 \\
& $\mathrm{MP} 2 / 6-311++\mathrm{G}(d, p)$ & 1.747 & 2.846 & 1.335 & 122.0 & 109.0 & 111.5 & 2.177 \\
& & 1 & 3 & 9 & & & & 2 \\
\hline \hline
\end{tabular}

are largely elongated $\left(R_{1}=3.245 \AA\right.$ and $R_{2}=2.835 \AA$ at point c). At point $d$ (time $=182 \mathrm{fs}$ ), one of the $\mathrm{C}-\mathrm{Cl}$ bonds is further elongated, whereas the other $\mathrm{C}-\mathrm{Cl}$ bond is shortened to the normal bond distance. Final, the $\mathrm{Cl}^{-}$ion is dissociated from $\mathrm{CF}_{2} \mathrm{Cl}_{2}^{-}$(point $e$ ).

\section{Energetics for the electron capture of $\mathrm{CF}_{2} \mathrm{Cl}_{2}\left(\mathrm{H}_{2} \mathrm{O}\right)_{3}$}

To elucidate the effect of the water cluster on the electron capture dynamics of $\mathrm{CF}_{2} \mathrm{Cl}_{2}$, a complex composed of $\mathrm{CF}_{2} \mathrm{Cl}_{2}$ and a cyclic water trimer, $\mathrm{CF}_{2} \mathrm{Cl}_{2}-\left(\mathrm{H}_{2} \mathrm{O}\right)_{3}$, is examined in the dynamics calculation. The potential energy curve for the electron capture process of $\mathrm{CF}_{2} \mathrm{Cl}_{2}\left(\mathrm{H}_{2} \mathrm{O}\right)_{3}$ is schematically illustrated in Fig. 3. The optimized structures of neutral and anionic states of $\mathrm{CF}_{2} \mathrm{Cl}_{2}\left(\mathrm{H}_{2} \mathrm{O}\right)_{3}$ are given in insert figures and the optimized parameters are given in Table II. In the neutral state, one of the chlorine atoms of $\mathrm{CF}_{2} \mathrm{Cl}_{2}$ orients to the $n$ orbital of $\mathrm{H}_{2} \mathrm{O}$ in the water trimer. The interaction distance is calculated to be $r_{1}=2.985 \AA$. The $\mathrm{C}-\mathrm{Cl}$ bond distances are calculated to be $R_{1}=1.785 \AA$ and $R_{2}$ $=1.771 \AA$, meaning that one of the $\mathrm{C}-\mathrm{Cl}$ bonds $\left(R_{1}\right)$ is slightly longer than that of the other one $\left(R_{2}\right)$. The $\mathrm{C}-\mathrm{Cl}$ bond length for the dangling $\mathrm{Cl}$ atom $(\mathrm{Cl})$ is longer than that of the $\mathrm{Cl}$ atom $\left(\mathrm{Cl}^{\prime}\right)$ interacting with the water molecule. Thus, the environment of two $\mathrm{Cl}$ atoms is different from each other in the case of the $\mathrm{CF}_{2} \mathrm{Cl}_{2}$ molecule adsorbed on the water cluster. This difference plays an important role in the electron capture dynamics on ice. Next, the anionic state of $\mathrm{CF}_{2} \mathrm{Cl}_{2}\left(\mathrm{H}_{2} \mathrm{O}\right)_{3}$ is fully optimized at the B3LYP/6-311+ $+\mathrm{G}(d, p)$ level. The $\mathrm{Cl}^{-}$ion of $\mathrm{CF}_{2} \mathrm{Cl}_{2}^{-}$is largely elongated, while the $\mathrm{Cl}^{-}$ion is solvated by three water molecules. The bond distances of $\mathrm{C}-\mathrm{Cl}$ atoms are calculated to be $R_{1}$ $=1.810 \AA$ and $R_{2}=2.661 \AA$. This complex is $30.3 \mathrm{kcal} / \mathrm{mol}$ lower in energy than the dissociation limit $\mathrm{Cl}^{-}$ $+\mathrm{CF}_{2} \mathrm{Cl}\left(\mathrm{H}_{2} \mathrm{O}\right)_{3}$. However, the trajectories for the electron capture of $\mathrm{CF}_{2} \mathrm{Cl}_{2}\left(\mathrm{H}_{2} \mathrm{O}\right)_{3}$ do not pass the complex region because the dangling $\mathrm{Cl}$ atom is preferentially dissociated from $\mathrm{CF}_{2} \mathrm{Cl}_{2}\left(\mathrm{H}_{2} \mathrm{O}\right)_{3}^{-}$, as shown in the next section.
The relative energies are calculated at three levels of theory: $\quad \mathrm{B} 3 \mathrm{LYP} / 6-311++\mathrm{G}(d, p), \quad \mathrm{MP} 4 \mathrm{SDQ} / 6-311$ $++\mathrm{G}(d, p) \| \mathrm{B} 3 \mathrm{LYP} / 6-311++\mathrm{G}(d, p), \quad$ and $\mathrm{MP} 2 / 6-311$ $++\mathrm{G}(d, p) \| \mathrm{MP} 2 / 6-311++\mathrm{G}(d, p)$ levels. The values are given in Fig. 3. All calculations give the similar energetics for the electron capture process of $\mathrm{CF}_{2} \mathrm{Cl}_{2}\left(\mathrm{H}_{2} \mathrm{O}\right)_{3}$. The complex is $30.3 \mathrm{kcal} / \mathrm{mol}$ lower in energy than the dissociation limit $\left[\mathrm{CF}_{2} \mathrm{Cl}\left(\mathrm{H}_{2} \mathrm{O}\right)_{3}+\mathrm{Cl}\right]$, while total available energy is calculated to be $16.2 \mathrm{kcal} / \mathrm{mol}$ at the B3LYP/6-311+ $+\mathrm{G}(d, p)$ level.

\section{Electron capture dynamics of $\mathrm{CF}_{2} \mathrm{Cl}_{2}-\left(\mathrm{H}_{2} \mathrm{O}\right)_{3}$ complex}

Snapshots of $\mathrm{CF}_{2} \mathrm{Cl}_{2}\left(\mathrm{H}_{2} \mathrm{O}\right)_{3}^{-}$after the electron capture obtained by the direct DFT-MD calculation are illustrated in Fig. 4. The structural parameters of the neutral complex are $R_{1}=1.785, \quad R_{2}=1.771, \quad$ and $r_{1}=2.985 \AA$, and $\theta=112.3^{\circ}\left(=<\mathrm{Cl}-\mathrm{C}-\mathrm{Cl}^{\prime}\right)$ at time zero (point $\left.a\right)$. One of the $\mathrm{Cl}$ atoms of $\mathrm{CF}_{2} \mathrm{Cl}_{2}$ (denoted by $\mathrm{Cl}^{\prime}$ ) is bound to the oxygen atom of the water trimer. At time $=68 \mathrm{fs}$, the dangling $\mathrm{C}-\mathrm{Cl}$ bonds $\left(R_{1}\right)$ is largely elongated, whereas the other one $\left(R_{2}\right)$ is slightly elongated after the electron capture $\left(R_{1}=2.905\right.$ and $\left.R_{2}=1.932 \AA\right)$. The parent radical $\left(\mathrm{CF}_{2} \mathrm{Cl}\right)$ is still bound to the water trimer $\left(r_{1}=3.029 \AA\right)$. At time $=267 \mathrm{fs}$, the $\mathrm{Cl}^{-}$ion is located at $R_{1}=6.019 \AA$, while the parent $\mathrm{CF}_{2} \mathrm{Cl}$ radical gradually goes away from the water cluster. Finally, the $\mathrm{Cl}^{-}$ ion is directly dissociated from $\mathrm{CF}_{2} \mathrm{Cl}_{2}^{-}$, while the parent radical is evaporated from the water cluster.

To elucidate the dynamics in more details, the profile of the potential energy and geometrical parameters calculated as a function of time are plotted in Fig. 5. Figure 5(a) shows the potential energy of the reaction system plotted as a function of time. Figures 5(b) and 5(c) show the distances $\left(R_{1}\right.$ and $\left.R_{2}\right)$ and angles $(\theta$ and $\phi)$, respectively. The zero level of the potential energy corresponds to the energy level at the vertical electron capture point of $\mathrm{CF}_{2} \mathrm{Cl}_{2}\left(\mathrm{H}_{2} \mathrm{O}\right)_{3}$ (total energy $=-1387.70188$ a.u.). After the electron capture, the potential energy decreases rapidly up to $-26.0 \mathrm{kcal} / \mathrm{mol}$ due 


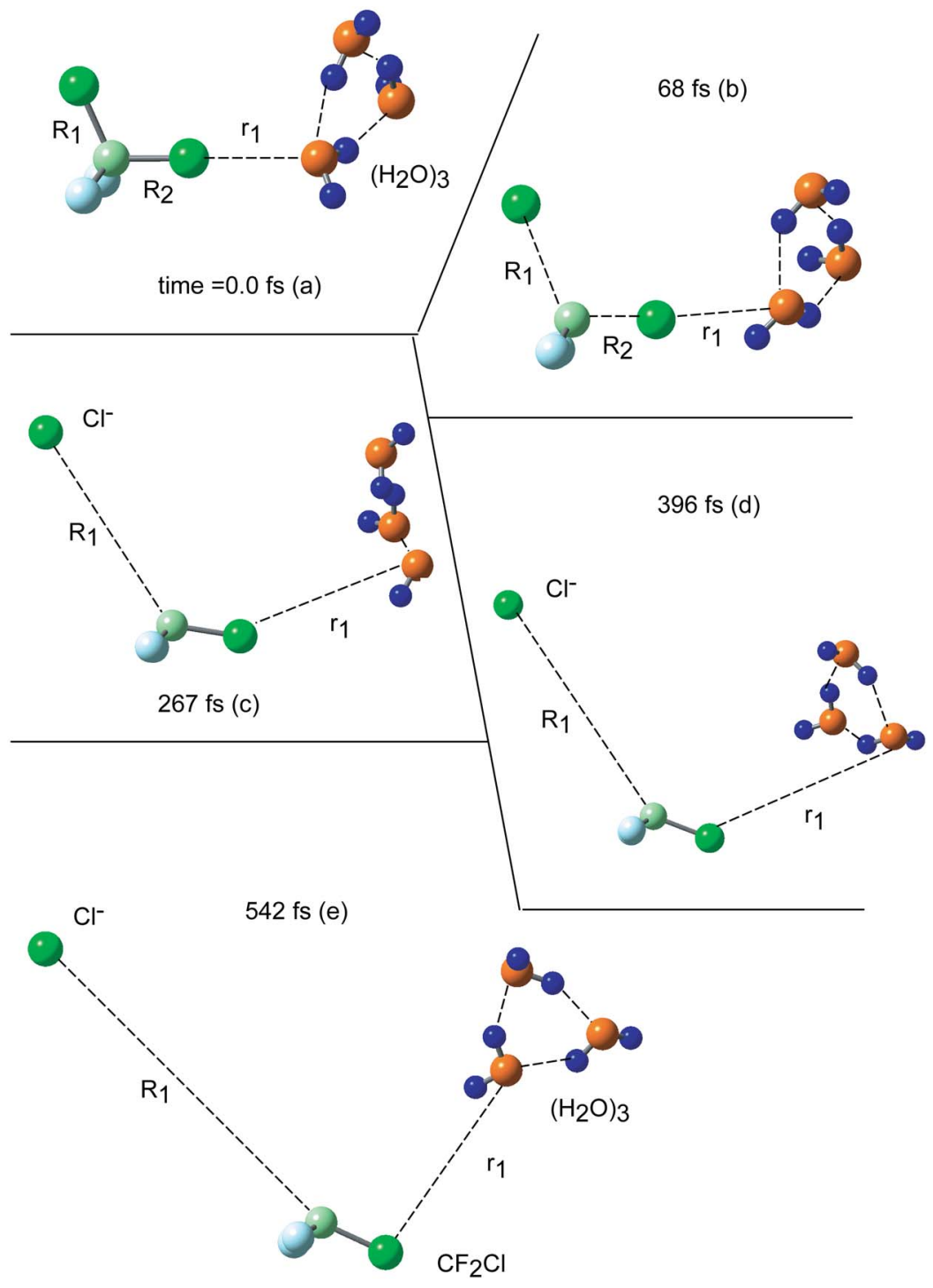

FIG. 4. (Color online) Snapshots for the electron capture reaction of $\mathrm{CF}_{3} \mathrm{Cl}_{2}\left(\mathrm{H}_{2} \mathrm{O}\right)_{3}$ obtained by the direct DFT-MD calculation at the B3LYP/6-311++G $(d, p)$ level.

to the elongation of one of the $\mathrm{C}-\mathrm{Cl}$ bonds of $\mathrm{CF}_{2} \mathrm{Cl}_{2}^{-}$. At point $b$ (time $=68 \mathrm{fs}$ ), the $\mathrm{C}-\mathrm{Cl}$ bond lengths are $R_{1}=2.905$ and $R_{2}=1.982 \AA$, indicating that the behavior of $\mathrm{CF}_{2} \mathrm{Cl}_{2}^{-}$on the water cluster is much different from that of free $\mathrm{CF}_{2} \mathrm{Cl}_{2}$ : Only one $\mathrm{C}-\mathrm{Cl}$ bond is rapidly elongated after the electron capture in the case of $\mathrm{CF}_{2} \mathrm{Cl}_{2}$ adsorbed on the water cluster, while the elongation of another $\mathrm{C}-\mathrm{Cl}$ bond is restricted by the water cluster. The $\mathrm{C}-\mathrm{Cl}$ distance and angle $\phi$ vibrate in the ranges of $1.710-1.910 \AA$ and $103^{\circ}-112^{\circ}$, respectively, indicating that the internal modes of the parent radical $\left(\mathrm{CF}_{2} \mathrm{Cl}\right)$ are still silent after the $\mathrm{Cl}^{-}$dissociation.

The relative center-of-mass translational energy between $\mathrm{Cl}^{-}$and $\mathrm{CF}_{2} \mathrm{Cl}\left(\mathrm{H}_{2} \mathrm{O}\right)_{3}$ is calculated to be $6.8 \mathrm{kcal} / \mathrm{mol}$ for this sample trajectory, which corresponds to $42 \%$ of the total available energy $(16.2 \mathrm{kcal} / \mathrm{mol})$. This indicates that about half of available energy is transferred efficiently into the translational mode of $\mathrm{Cl}^{-}$, which is much different from the energy redistribution in $\mathrm{CF}_{2} \mathrm{Cl}_{2}$ in gas phase.

Thus, the dangling $\mathrm{Cl}$ atom is rapidly dissociated from $\mathrm{CF}_{2} \mathrm{Cl}_{2}^{-}$as a $\mathrm{Cl}^{-}$ion after the electron capture in the case of $\mathrm{CF}_{2} \mathrm{Cl}_{2}$ on the water cluster. Almost all of the available energy is mainly transferred into the translational energy of the $\mathrm{Cl}^{-}$ion. On the other hand, in free $\mathrm{CF}_{2} \mathrm{Cl}_{2}^{-}$, two $\mathrm{C}-\mathrm{Cl}$ bonds of $\mathrm{CF}_{2} \mathrm{Cl}_{2}^{-}$are equivalently and largely elongated, and then one of the $\mathrm{Cl}^{-}$ions is dissociated from $\mathrm{CF}_{2} \mathrm{Cl}_{2}^{-}$. Therefore, almost all of the total available energy is transferred mainly into the internal modes of the parent $\mathrm{CF}_{2} \mathrm{Cl}$ radical.

\section{E. Effects of initial structures of neutral states on the dynamics}

In an actual system, the structures of $\mathrm{CF}_{2} \mathrm{Cl}_{2}$ and $\mathrm{CF}_{2} \mathrm{Cl}_{2}\left(\mathrm{H}_{2} \mathrm{O}\right)_{3}$ are fluctuated around the equilibrium structures. To include the effects, geometrical configurations are randomly generated around the optimized structure, and then ten dynamics calculations are run from the selected points. The geometries are selected so as to that the energy differences from that of the optimized geometry are lower than $0.5 \mathrm{kcal} / \mathrm{mol}$ at the neutral state.

The results of direct DFT-MD calculations from the ten geometrical configurations of $\mathrm{CF}_{2} \mathrm{Cl}_{2}$ are given in Fig. 6(a) together with that of the optimized geometry. All trajectories pass along the same route up to $100 \mathrm{fs}$. After the time region (100 fs), the routes of the trajectories are slightly different each other. All trajectories give the same product $\mathrm{Cl}^{-}$ $+\mathrm{CF}_{2} \mathrm{Cl}$. The average of the relative translational energy is 

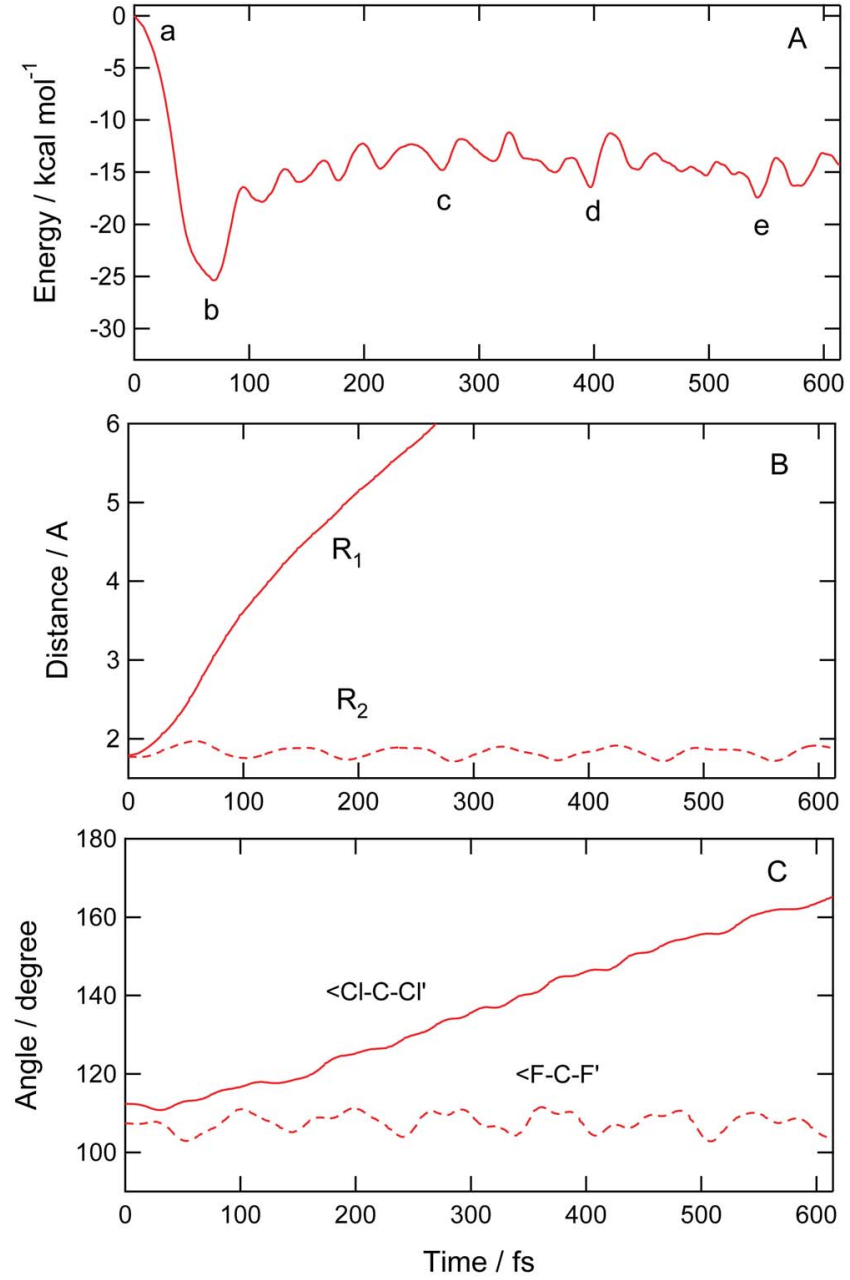

FIG. 5. (Color online) Time propagations of the potential energy (A), distances $\left(R_{1}\right.$ and $\left.R_{2}\right)(\mathrm{B})$, and angles $\left(<\mathrm{Cl}-\mathrm{C}-\mathrm{Cl}^{\prime}\right.$ and $\left.<\mathrm{F}-\mathrm{C}-\mathrm{F}^{\prime}\right)$ for the electron capture reaction of $\mathrm{CF}_{3} \mathrm{Cl}_{2}\left(\mathrm{H}_{2} \mathrm{O}\right)_{3}$. The direct DFT-MD calculation was carried out at the $\mathrm{B} 3 \mathrm{LYP} / 6-311++\mathrm{G}(d, p)$ level.

calculated to be $3.7 \mathrm{kcal} / \mathrm{mol}$ which is $14.2 \%$ of the total available energy. Figure 6(b) shows the results for $\mathrm{CF}_{2} \mathrm{Cl}_{2}\left(\mathrm{H}_{2} \mathrm{O}\right)_{3}$. The routes of all trajectories are close to that of the optimized structure. The translational energy is $7.26 \mathrm{kcal} / \mathrm{mol}$. This energy is $44.8 \%$ of the total available energy for the reaction. Thus, it can be concluded that the translational energy of $\mathrm{Cl}^{-}$formed from $\mathrm{CF}_{2} \mathrm{Cl}_{2}$ adsorbed on ice is significantly larger than that in the gas phase.

\section{DISCUSSION}

\section{A. Model of electron capture dynamics of $\mathrm{CF}_{2} \mathrm{Cl}_{2}$ in gas phase and on ice surface}

On the basis of the present results, we would like to propose a model for the electron capture dynamics of $\mathrm{CF}_{2} \mathrm{Cl}_{2}$ in gas phase and on the ice surface. The schematic illustration of the model is given in Fig. 7. In the electron capture in gas phase, the excess electron is distributed symmetrically on both $\mathrm{Cl}$ atoms of $\mathrm{CF}_{2} \mathrm{Cl}_{2}$ at the vertical electron capture point. Both the $\mathrm{C}-\mathrm{Cl}$ bonds are largely elongated after the electron capture, while one of the $\mathrm{Cl}$ atoms of $\mathrm{CF}_{2} \mathrm{Cl}_{2}^{-}$is dissociated from $\mathrm{CF}_{2} \mathrm{Cl}_{2}^{-}$as a $\mathrm{Cl}^{-}$ion. This bond elongation
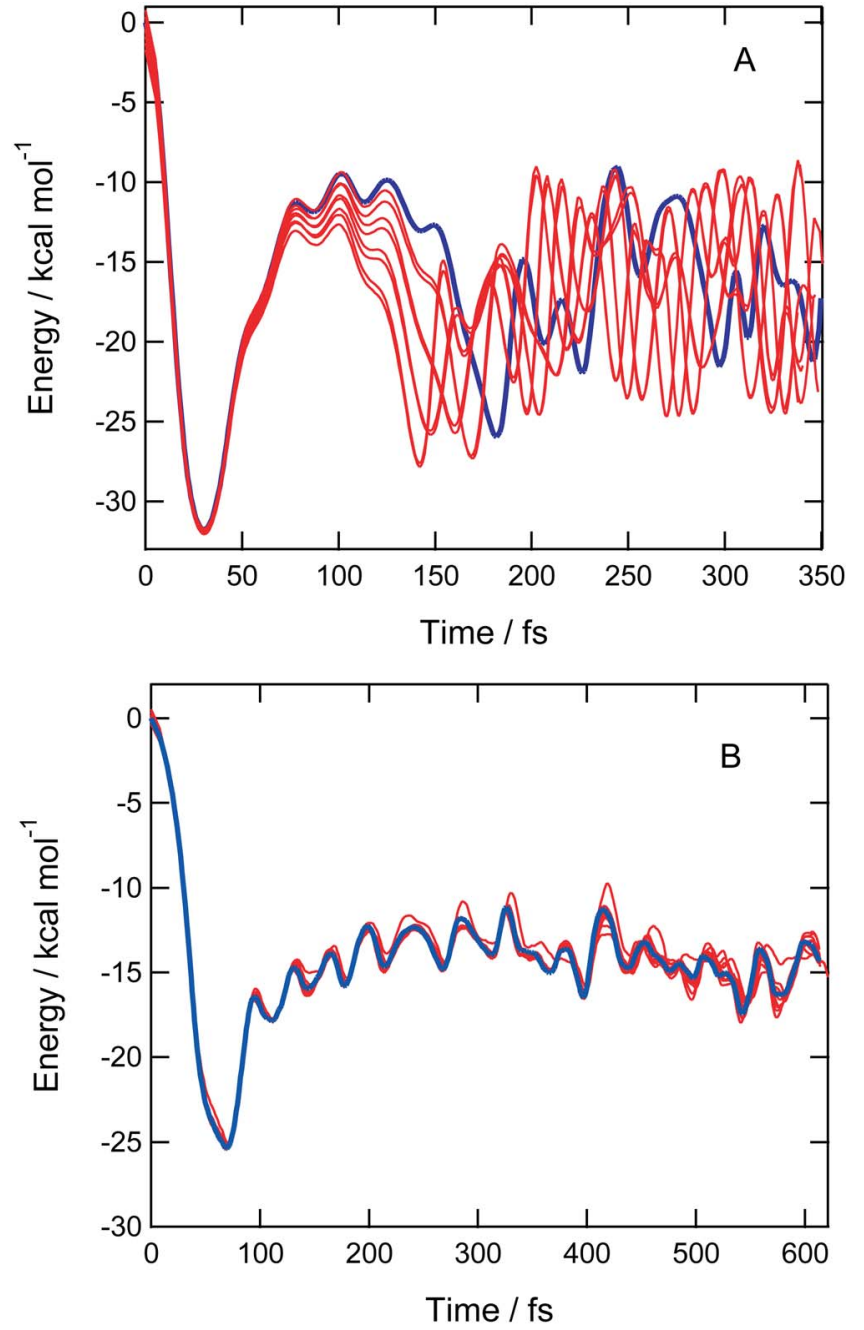

FIG. 6. (Color online) Effects of initial conditions on the electron capture dynamics of (A) $\mathrm{CF}_{3} \mathrm{Cl}_{2}\left(\mathrm{H}_{2} \mathrm{O}\right)_{3}$ and $(\mathrm{B}) \mathrm{CF}_{3} \mathrm{Cl}_{2}\left(\mathrm{H}_{2} \mathrm{O}\right)_{3}$. Potential energies after an electron attachment obtained by direct ab initio $\mathrm{MD}$ calculation are plotted as a function of time. Thick curves indicate that the trajectories are from the optimized structures. Ten trajectories are run from selected points generated randomly around the optimized structures.

causes the increase of the internal energy of the parent $\mathrm{CF}_{2} \mathrm{Cl}$ radical and low translational energy of $\mathrm{Cl}^{-}$(slow $\mathrm{Cl}^{-}$ion).

On the other hand, the situation of the electron capture of $\mathrm{CF}_{2} \mathrm{Cl}_{2}$ adsorbed on the ice is much different from that in gas phase. Since one of the $\mathrm{Cl}$ atoms of $\mathrm{CF}_{2} \mathrm{Cl}_{2}$ binds to the oxygen atom of the water molecule of the ice surface, the $\mathrm{Cl}$ atoms of $\mathrm{CF}_{2} \mathrm{Cl}_{2}$ are not equivalent to each other. After the electron capture of $\mathrm{CF}_{2} \mathrm{Cl}_{2}$ on the ice, the excess electron and spin densities are not equivalently distributed on the $\mathrm{Cl}$ atoms. Immediately, only the $\mathrm{Cl}^{-}$ion (dangling $\mathrm{Cl}$ atom) is directly dissociated from $\mathrm{CF}_{2} \mathrm{Cl}_{2}^{-}$. The internal modes of the parent $\mathrm{CF}_{2} \mathrm{Cl}$ radical are still close to the vibrationally ground state. The total available energy is efficiently transferred into the translational mode of $\mathrm{Cl}^{-}$(the dangling $\mathrm{Cl}$ atom). Therefore, it can be predicted that the fast $\mathrm{Cl}^{-}$ion is observed experimentally in the case of $\mathrm{CF}_{2} \mathrm{Cl}_{2}$ on ice.

From these results, we can predict a distribution of the translational energy of $\mathrm{Cl}^{-}$(population) formed from $\mathrm{CF}_{2} \mathrm{Cl}_{2}$ in gas phase and on ice. The population of $\mathrm{Cl}^{-}$formed by the gas phase reaction has a maximum at very low energy re- 
A
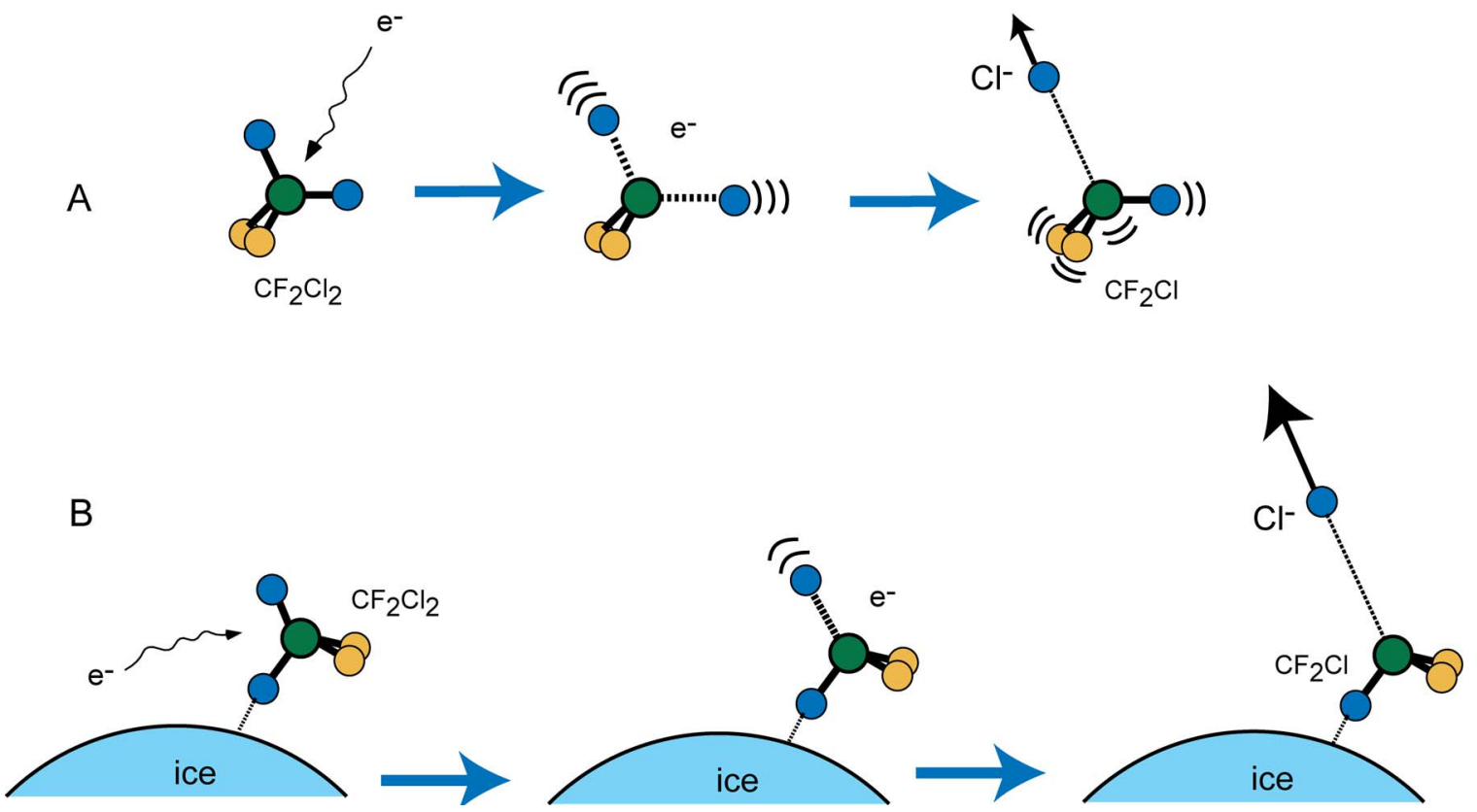

FIG. 7. Reaction model for the electron capture dynamics of $\mathrm{CF}_{2} \mathrm{Cl}_{2}$ in gas phase (A) and $\mathrm{CF}_{2} \mathrm{Cl}_{2}$ absorbed on water ice (B).

gion, whereas that of the reaction on ice has a minimum at higher energy regions. From the present calculation at the B3LYP/6-311++ $\mathrm{G}(d, p)$ level, it can be roughly estimated that the peaks for $\mathrm{Cl}^{-}$in gas phase and ice are 3.7 and $7.3 \mathrm{kcal} / \mathrm{mol}$, respectively.

\section{B. Comparison with experiments}

Recently, chemical reactions of molecules adsorbed on water ice have been observed experimentally by several groups. ${ }^{24}$ One of the topics large enhancements in the dissociative electron attachment of molecules adsorbed on water ice. Lu and Sanche reported that the dissociative electron attachment to $\mathrm{HCl}$ is strongly enhanced by adsorption on the surface of water ice. The enhancement is due to electron transfer from precursor states of the solvated electron on the ice surface to the $\mathrm{HCl}$ molecule. ${ }^{4}$ In the case of $\mathrm{CF}_{2} \mathrm{Cl}_{2}, \mathrm{Lu}$ and Madey reported that the large enhancement of formations of $\mathrm{Cl}^{-}$and $\mathrm{F}^{-}$is observed in $\mathrm{CF}_{2} \mathrm{Cl}_{2}$ on $\mathrm{H}_{2} \mathrm{O} / \mathrm{NH}_{3}$ ice. $^{5,25}$

The present study suggests that the population of the translational energy of $\mathrm{Cl}^{-}$ions is distributed at the high energy region (fast $\mathrm{Cl}^{-}$ion) if the electron capture occurred from the halocarbon absorbed on ice. On the other hand, the electron capture in gas phase leads to a slow $\mathrm{Cl}^{-}$ion. Thus, the measurement of the translational energy of the halogen ion is important in the detection of the origin of the halocarbon.

\section{Additional comments}

We have introduced several approximations to calculate the potential energy surface and to treat the reaction dynamics. Firstly, we have assumed that the anionic states at the vertical electron capture point have no excess energy at the initial step of the trajectory calculation (time $=0.0 \mathrm{ps}$ ). Also, we neglected zero-point vibrational energies in the dynamics calculation because these energies were close each other in neutral and anionic states (the difference was less than $2.05 \mathrm{kcal} / \mathrm{mol})$. Therefore, this approximation is enough to describe the dynamics of the present system. The inclusion of these effects on the dynamics calculations may cause a slight change of the lifetime of the complex. In the case of a higher excess energy, the lifetime of the intermediate complex will become shorter.

Secondly, we used a cyclic water trimer $\left(\mathrm{H}_{2} \mathrm{O}\right)_{3}$ as a model of water ice. This size may be small to treat as a model of water ice. However, the direct DFT-MD calculation spends a long CPU time. Hence, now, this model might be limited to treat the effect of the water cluster on the electron capture dynamics of halocarbon in our computer facility. In the present study, the structural conformation whose $\mathrm{Cl}$ atom of the $\mathrm{CF}_{2} \mathrm{Cl}_{2}$ binding to the oxygen atom of $\left(\mathrm{H}_{2} \mathrm{O}\right)_{3}$ was used as an initial structure because this form is the optimized structure of $\mathrm{CF}_{2} \mathrm{Cl}_{2}\left(\mathrm{H}_{2} \mathrm{O}\right)_{3}$. In an actual ice surface, there is a dangling hydrogen of $\mathrm{H}_{2} \mathrm{O}$, and the hydrogen may be bound to the $\mathrm{Cl}$ atom of $\mathrm{CF}_{2} \mathrm{Cl}_{2}$. The calculation with larger water clusters is effective to simulate such case.

Lastly, we assumed a B3LYP/6-311++ $\mathrm{G}(d, p)$ multidimensional potential energy surface in the dynamics calculations throughout. To check validity of a single configuration description, symmetry adapted cluster-configuration (SACCI) and complete active space self-consistent field (CASSCF) calculations with a $6-31+\mathrm{G}^{*}$ basis set have been carried out for some points obtained by the dynamics calculations. The coefficients of HF configurations are larger than 0.95 at all points. Also, the energy gaps between ground and first excited states are larger than $0.8-3.0 \mathrm{eV}$. Therefore, the single reference description would be effective to obtain the qualitative feature of the present reaction dynamics. However, more accurate wave functions may provide a deeper insight in the dynamics. Despite the several assumptions in- 
troduced here, the results enable us to obtain valuable information on the mechanism of the electron capture dynamics of halocarbon on water ice.

\section{ACKNOWLEDGMENTS}

The authors are indebted to the Computer Center at the Institute for Molecular Science (IMS) for the use of the computing facilities. They also acknowledge a partial support from a Grant-in-Aid for Scientific Research (C) from the Japan Society for the Promotion of Science (JSPS).

${ }^{1}$ V. Ramaswamy, M. D. Schwarzkopf, and K. P. Shine, Nature (London) 355, 810 (1992).

${ }^{2}$ C. Y. Hsu, H. Y. Huang, and K. C. Lin, J. Chem. Phys. 123, 134312 (2005).

${ }^{3}$ O. B. Toon and R. P. Turco, Sci. Am. 264, 68 (1991).

${ }^{4}$ Q.-B. Lu and L. Sanche, Phys. Rev. Lett. 87, 078501 (2001).

${ }^{5}$ Q. B. Lu and T. T. Madey, Surf. Sci. 451, 238 (2000).

${ }^{6}$ K. Nagesaha and L. Sanche, Phys. Rev. Lett. 81, 5892 (1998).

${ }^{7}$ C. C. Perry, G. M. Wolfe, A. J. Wagner, J. Torres, N. S. Faradzhev, T. E. Madey, and D. H. Fairbrother, J. Phys. Chem. B 107, 12740 (2003).

${ }^{8}$ C. C. Perry, N. S. Faradzhev, D. H. Fairbrother, and T. E. Madey, Int.
Rev. Phys. Chem. 23, 289 (2004).

${ }^{9}$ R. E. Honrath, M. C. Peterson, S. Guo, J. E. Dibb, P. B. Shepson, and B. Campbell, Geophys. Res. Lett. 26, 695 (1999).

${ }^{10}$ R. E. Honrath, S. Guo, M. C. Peterson, M. P. Diiobak, J. E. Dibb, and M. A. Arsenault, J. Geophys. Res. 105, 24183 (2000).

${ }^{11}$ R. L. Hudson and M. H. Moore, J. Geophys. Res., [Planets] 106, 33275 (2001).

${ }^{12}$ J. E. Schaff and J. T. Roberts, Surf. Sci. 426, 384 (1999).

${ }^{13}$ J. E. Schaff and J. T. Roberts, J. Phys. Chem. 100, 14151 (1996).

${ }^{14}$ C. Monca and A. Allouche, J. Chem. Phys. 114, 4226 (2001).

${ }^{15}$ S. Picaud, C. Toubin, and C. Girardet, Surf. Sci. 103, 178 (2000).

${ }^{16}$ G. Bussolin, S. Casassa, C. Pisani, and P. Ugliengo, J. Chem. Phys. 108, 9516 (1998).

${ }^{17}$ N. S. Faradzhev, C. C. Perry, D. O. Kusmierek, D. H. Fairbrother, and T. E. Madey, J. Chem. Phys. 121, 8547 (2004).

${ }^{18}$ Q. B. Lu and L. Sanche, J. Chem. Phys. 115, 5711 (2001).

${ }^{19}$ Q. B. Lu and L. Sanche, J. Chem. Phys. 120, 2434 (2004).

${ }^{20}$ H. Tachikawa, J. Phys. Chem. A 101, 7454 (1997).

${ }^{21}$ H. Tachikawa, J. Chem. Phys. 125, 13311 (2006).

${ }^{22}$ H. Tachikawa, J. Chem. Phys. 125, 144307 (2006).

${ }^{23}$ M. J. Frisch, G. W. Trucks, H. B. Schlegel et al., Gaussian03, Revision B.04 (Gaussian, Inc., Pittsburgh, PA, 2003).

${ }^{24}$ S. Leutwyler, Nature (London) 417, 230 (2002).

${ }^{25}$ Q.-B. Lu and T. E. Madey, J. Phys. Chem. B 105, 2779 (2001). 